\title{
Assessment of new drugs: a clinical pharmacologist's view*
}

\author{
A M BRECKENRIDGE
}

One of the central roles of the clinical pharmacologist is the assessment of new drugs in man and in this respect he has a necessarily close relationship with the pharmaceutical industry. $\mathrm{He}$ is largely dependent on industry for the production of new chemical entities; but his independence of judgment must be preserved at all costs. Industry in its turn appreciates that competent independent arbiters of their new products are important for its prosperity. Currently both parties, clinical pharmacology and industry, feel threatened by a third party, governmental drug regulatory authorities. The purpose of this article is to delineate problems currently faced by the clinical pharmacologist in assessing new drugs and to suggest some possible solutions.

\section{Background}

The assessment of new chemical entities in man progresses in four phases. In the first phase the drug, already tested satisfactorily in animals, is given to human volunteers in doses initially too small to have a therapeutic effect, the aims being to compare the pharmacology of the compound with results previously obtained in animals and to examine how man tolerates it. In Britain (but not in the United States) phase I studies may be done without governmental permission, but clearly ethical consent is required. A clinical trials certificate must be granted by Department of Health and Social Security (DHSS) before the drug is given to any patient in the second phase of its evaluation in man. Only a few patients-40 or 50-may be given the drug in this phase II development, since the aim is to discover if the pharmacological effect discovered in preclinical

*Based on a paper given at a meeting sponsored by the Society for Drug Research on risk-benefit analysis in drug research held in Canterbury in March 1980.

Department of Pharmacology and Therapeutics, University of Liverpool, Liverpool L69 3BX

A M BRECKENRIDGE, MD, FRCP, professor of clinical pharmacology testing has a therapeutic parallel. If confirmed, the drug passes into clinical trial-phase III of its development-in which many patients (let us say several hundreds) will be studied to compare its therapeutic effect either with placebo or with a well-established treatment for the condition. If all is still on course the company will return to DHSS at the completion of clinical trials and request permission to market the drug, for which they require a product licence. Once marketed, careful study of the safety record of the drug is paramount, and this part of its development has been termed phase IV, or post-marketing surveillance, whose conduct is currently the matter of much debate.

\section{Parties concerned}

Many parties are concerned in these evaluation processes and each has aims and expectations which it hopes to achieve. Industry is intent on getting its new chemical entity on to the market as quickly as possible. The drug regulatory authority, thalidomide sitting on its shoulder, attempts to license only safe and effective compounds. Medical science works to see its breakthroughs translated into therapeutic reality. The public demand more effective, yet safe, drugs for disease, and look to the medical practitioner to prescribe them. The media monitor and report the moves of all parties.

\section{The problems}

\section{PROBLEM 1}

Over the past two decades the number of new chemical entities given to man has decreased, ${ }^{1}$ and there is some evidence that this decline has been more protracted in the United States than in Britain. Several reasons have been advanced for these changes. A fall in chemical inventiveness and a progressive decrease in understanding human disease processes (the so-called knowledge-depletion theory) have been seriously advanced. But any reader of current published medical scientific reports, assailed by 
the exponential increase in publications on both disease processes and the drugs to treat them would find these hypotheses hard to justify, although he would probably agree that most of the easy drug discoveries have now been made. One contributing and relevant cause is the increased costs of drug research and development, when a fixed budget may well impose constraints on new drug research. Between $£ 20 \mathrm{~m}$ and $£ 40 \mathrm{~m}$ are now considered the realistic cost of putting a new drug on the market, before any capital return is made.

In the view of many people one, if not the principal, cause of the decrease in new chemical entities going into man is the proliferation of regulations at all stages of the drug's development.

\section{Consequence 1}

Whatever the reason, one possible result of a decrease in new chemical entities going into man is a diminution in innovative drug use. Many important therapeutic uses of a drug cannot be predicted when the drug is first tested, and obviously, the earlier during evaluation the development of the drug is discontinued for fiscal or financial reasons, the less searching is the assessment of the ultimate value of that drug. Table I lists drugs and the uses that were only realised after the drug had been introduced into clinical medicine for other purposes.

TABLE I-Major disease entities treated by drugs not introduced for that purpose

\begin{tabular}{ll}
\hline \multicolumn{1}{c}{ Drug } & Disease treated \\
\hline Propranolol & Hypertension \\
Sulphinpyrazone & Ischaemic heart disease \\
Diazepam & Status epilepticus \\
Phenobarbitone & Epilepsy \\
Chlorpromazine & Schizophrenia \\
Oestrogens/progestogens & Contraception \\
Imipramine & Depression \\
Probenecid & Gout \\
Lignocaine & Arrhythmias \\
\hline
\end{tabular}

\section{PROBLEM 2}

If there are fewer $n \geq w$ chemical entities available for clinical assessment clearly this situation will also apply to Britain. But are there reasons why the situation here might be more critical than elsewhere? Table II shows a recent estimate of durations required to carry out the necessary tests on a new chemical entity and to prepare reports in the form required for obtaining a clinical trials certificate, together with the duration taken by drug regulatory authorities to process these reports in five countries ( $P$ Bayliss in a paper on preclinical testing of new medicines at a medicopharmaceutical forum in London in 1979). Bayliss emphasises that these durations assume that the

TABLE II-Duration before clinical testing of new chemical entities

\begin{tabular}{|c|c|c|c|c|c|}
\hline & USA & Sweden & Germany & Holland & Britain \\
\hline $\begin{array}{l}\text { Carrying out tests (weeks) } \\
\text { Processing time (weeks) }\end{array}$ & $\begin{array}{c}24-36 \\
4\end{array}$ & $\begin{array}{c}24-36 \\
2\end{array}$ & $\begin{array}{c}24-36 \\
0\end{array}$ & $\begin{array}{c}24-36 \\
2-4\end{array}$ & $\begin{array}{r}52-130 \\
26-32\end{array}$ \\
\hline
\end{tabular}

Reproduced by kind permission of Dr Paul Bayliss of ICI Pharmaceutical Company.

pharmaceutical company concerned is able to devote all its effort at one time to the compound (which is clearly rarely possible, but reasonable for comparative purposes). In Britain regulations for completed fertility studies may increase the testing time to 52 weeks, and should the compound be one on which the drug regulatory authorities require a carcinogenicity study-for instance, a beta-adrenoceptor blocking agent-then the period could be as long as 130 weeks before a single dose is given to patients.

\section{Consequence 2}

There would appear to be a great disincentive for industry to do its phase 2 studies in Britain. In practice this is true, for when I approached the medical directors of five British-based pharmaceutical companies with the question "What percentage of your phase II (early clinical) studies has your company carried out in Britain in 1977-9 ?" the responses (with comments) were as given in table III. The consequences of these findings for British

TABLE III-Percentage early phase 2 studies done in Britain 1977-9

\begin{tabular}{|c|c|c|}
\hline Company & $\%$ & Comment \\
\hline $\begin{array}{l}\mathbf{A} \\
\mathbf{B} \\
\mathbf{C}\end{array}$ & $\begin{array}{l}0 \\
0 \\
0\end{array}$ & \multirow{2}{*}{$\begin{array}{l}\text { "Doing more and more in USA" } \\
\text { "Feel very guilty about it" } \\
\text { "Spent f60 } 600 \text { on early phase } 2 \text { last year. Would have } \\
\text { liked this to go to UK units" } \\
\text { "Doing more and more in USA" } \\
\text { "If quick data needed, going abroad. If long programme } \\
\text { anticipated some done in UK" }\end{array}$} \\
\hline$\underset{\mathrm{E}}{\mathrm{D}}$ & $\begin{array}{l}10 \\
30\end{array}$ & \\
\hline
\end{tabular}

clinical pharmacology are clear. The testing of new compounds in patients is one of the most challenging aspects of clinical pharmacology, where difficult clinical decisions must often be made. Because of the small number of phase 2 studies being carried out here, British clinical pharmacologists rarely have the chance to make these decisions or do this type of work. Since initial patient-drug exposure usually takes place abroad, foreign clinical pharmacologists are rapidly gaining the expertise from testing new drugs produced in Britain by British companies.

\section{PROBLEM 3}

The pharmaceutical industry appreciates that the standard of investigative medicine in Britain is high. Further, it is widely known that academic units are relatively starved of financial resources. Thus industry comes to specialist units not for phase II studies but with the request to do phase III (clinical trial) work. Frequently they have already composed the protocols for these studies, which are aimed at satisfying the specific requirements of one drug regulatory authority.

\section{Consequence 3}

The clinical investigator is immediately in a dilemma. He soon realises that his scientific input into the project and also the scientific output may be very limited. He may have to employ a clinical research assistant or the equivalent specifically for the work. The calibre of a person prepared to take on this type of work may not be high, and thus the overall standard of the unit may fall. On the other hand, the money paid for this contractual work may solve some immediate departmental requirements. There is no easy solution to this.

\section{PROBLEM 4}

Not all the ills that befall clinical pharmacology can be laid at the door of the drug regulatory authorities. There is a current tendency for pharmaceutical companies to do much phase I (volunteer) work "in house" rather than farm this out to units in the NHS or universities. When I asked the same five medical directors of British-based pharmaceutical houses the question "What percentage of human volunteer studies (phase I) has your company carried out "in house" in 1978-9 ?" the answers and comments given are shown in table IV. There is only a small

TABLE IV-Percentage phase 1 studies done "in house" 1978-9

\begin{tabular}{crc}
\hline Company & $\%$ & \\
\hline A & 100 & "Better supply of volunteers than in academic units" \\
B & 95 & "Very convenient. No shipping of samples or methods" \\
C & 75 & \\
E & 80 & "We are building up our facilities and hope to do more" \\
\hline
\end{tabular}


amount of phase I work being done in the specialist units, be they funded by the NHS or a university.

It is relevant at this point to ask what are the necessary skills expected of a clinical investigator working on new drug studies in man.

(1) He must be a competent clinician, trained in general medicine and in the primary area for which the new drug is intended-for instance, hypertension, rheumatoid arthritis, or depression. Further, he must be able to deal expertly with any unforeseen event that may arise during the testing of the new drug.

(2) He must be trained in the methodology of clinical research. As Dollery ${ }^{2}$ has recently discussed, this is one of the most difficult disciplines for the young doctor to learn, and without training he performs extremely badly in clinical research.

\section{Consequence 4}

These trends, the decrease in phase II and phase I studies and the increase in phase III studies, all militate against the training of the competent investigator, be he destined for industry, academia, or the NHS. Further, the less well trained he is, the less likely is he to light on unexpected therapeutic drug activity of the type mentioned previously (fig).

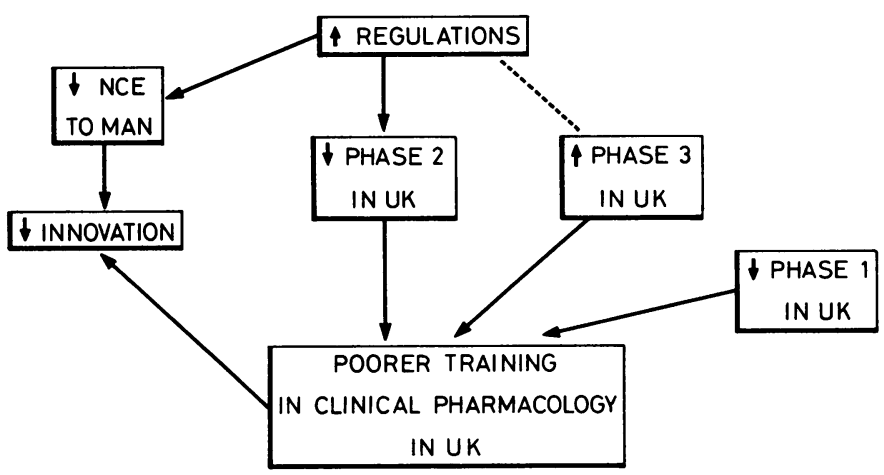

Influences relevant to poorer training of clinical pharmacologists in Britain.

\section{Solutions}

(1) Clinical pharmacology must be prepared to shoulder more responsibility. This does not only mean serving on the appropriate drug regulatory authority committees as individuals but speaking as a discipline with a corporate voice on appropriate matters. Drug safety is obviously a political matter, but it must be based on scientific principles; if there is little scientific basis for the proliferation of animal testing that prevents new drugs being given to man, then the scientist-that is, the clinical pharmacologist-must say so.

(2) Clinical pharmacology must be prepared to collaborate more closely with industry. Many academic departments have members of the pharmaceutical industry working as part-time research fellows. The future may well lie in joint formal appointments, with the clinical investigator in training spending time both in industry and an academic unit. The CASE system for science postgraduates works well; why should we not try the same in clinical pharmacology?

(3) The public must be educated in their expectations by clinical pharmacologists. The demand for novel drugs cannot be satisfied without running the risk of adverse reactions. Prescription of any drug by a doctor is a clinical trial and not a guarantee of instant success. How far the individual patient should be drawn into the decision-making process of drug prescribing is a contentious problem, but the process of drug prescribing at present is too one sided. These problems are clearly spent out in the most excellent book The Medicine you $T a k e,{ }^{3}$ and the debates therein must be given more publicity.

\section{Conclusions}

The aims of drug regulations for the approval of new medicines would appear to be two: firstly, to ensure a level of drug safety acceptable to the public, the doctor, science, and industry; and, secondly, to allow the development of important new medicines by stimulating both basic research and clinical pharmacology. The first of these aims should not be achieved at the price of the second.

These are some problems associated with new drug development, their consequences, and possible solutions as seen from the standpoint of one clinical pharmacologist. The drug regulator, the manufacturer, the public, and the media will also have views on these matters. I welcome the chance to state my position.

\section{References}

1 Wardell WM. More regulation or better therapies? University of Rochester: Centre for Drug Development, 1979. (Reprint series.)

${ }^{2}$ Dollery CT. The end of an age of optimism: medical science in retrospect and prospect. London: Nuffield Provincial Hospital Trust, 1978. (Rock Carling Fellowship, 1978.)

3 Laurence DR, Black JW. The medicine you take. London: Croom, Helm, 1978.

(Accepted 28 April 1980)
Can ethamsylate (Dicynene) or other haemostatic agents be used as an emergency measure in people with haemorrhage?

Haemorrhage due to specific bleeding disorders should be treated where possible by correcting the defect-for example, by transfusion of a missing clotting factor, fresh frozen plasma, or fresh platelets, or administration of vitamin $\mathrm{K}$. In the absence of a correctable defect local measures to arrest bleeding should be tried first. Only if these fail or are impracticable should the use of a haemostatic drug be considered. Topical haemostatic agents, such as oxidised cellulose and absorbable gelatin sponge, will reduce capillary bleeding but have little effect on bleeding from arteries or veins. Their usefulness is therefore limited.

The systemic haemostatic drugs available include epsilon aminocaproic acid (Epsikapron), tranexamic acid (Cyklokapron), and ethamsylate (Dicynene). Epsilon aminocaproic acid and tranexamic acid are antifibrinolytic agents and are effective in reducing bleeding after prostatectomy, tonsillectomy, and dental extraction; and in primary menorrhagia. The precise mechanism of action of ethamsylate is not known, but it reduces the bleeding time by effects on both platelets and capillary walls. It is effective in primary menorrhagia but clinical evidence that it is effective in other conditions is inadequate. I am not aware of any good evidence that systemic haemostatic drugs are of any value in controlling acute haemorrhage in conditions other than those mentioned above.

Verstraete M. Haemostatic drugs. A critical appraisal. The Hague: Martinus Niihoff Medical Division, 1977.

What is the most practicable test for determining acetylator phenotype?

A simple method ${ }^{1}$ for determining acetylator phenotype uses a small dose of sulphadimidine, and only one serum and one trine specimen need be collected. The specimens need no special handling and laboratory analysis is simple. ${ }^{2}$ There is very little overlap between fast and slow acetylators when determining their state by this method.

1 Price Evans DA. An improved and simplified method of detecting the acetylator phenotype. $₹$ Med Genet 1969;6:405.

Varley H. Practical Clinical Biochemistry. London: Heinemann Medical, 1967:

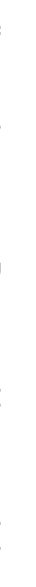

